\title{
The Preparation and Characterization of Cell Walls and the Preparation of Flagella of Vibrio fetus
}

\author{
By R. F. KEELER, A. E. RITCHIE, J. H. BRYNER AND \\ JANE ELMORE \\ National Animal Disease Laboratory, Animal Disease and \\ Parasite Research Division, ARS, USDA, Ames, Iowa, U.S.A.
}

(Received 2 November 1965)

\section{SUMMARY}

Methods are described for the preparation of cell-wall material and flagella from Vibrio fetus. In common with certain other Gram-negative organisms $V$. fetus apparently possesses a three-layer wall which, it is proposed, consists of an outer lipoprotein layer, a middle lipo-polysaccharide layer, and an inner mucopeptide layer. These layers were studied chemically and by electron microscopy after various extraction and enzymic degradation procedures with whole-wall material. None of the layers of the wall was found to possess a microscopically discernible substructure, although the extracted lipopolysaccharide agglomerated into a characteristic stringy array. The probable function, contribution to cellular rigidity, and composition of the wall layers is discussed.

\section{INTRODUCTION}

Many aspects concerning the nature of the limiting surface and other structural entities of bacterial cells have been elucidated during the past few years. Reviews on the subject attest to the productive activity in the field (Salton, 1960, 1964; Mitchell, 1959; Leifson, 1960; Weidel \& Pelzer, 1964). Interest has been generated in surface structures because of the important functional role played by the wallmembrane complex, the apparent antigenic importance of these structures, and because of the relative ease of fractionation of material to allow convenient preparations for chemical characterization studies. Most of the activity has concerned Gram-positive organisms because of the greater simplicity of composition and organization (Cummins \& Harris, 1956), although Gram-negative organisms have more recently come under scrutiny (Weidel, Frank \& Martin, 1960; Murray, 1963). We are investigating the cytochemistry, structural organization, and antigenic characteristics of Vibrio fetus, a Gram-negative pathogen of domestic animals. We report here on the preparation of purified walls and flagella and on certain characteristics of these structural entities.

\section{METHODS}

Organisms and culture methods. Vibrio fetus strain 436 was used throughout as the model organism. For certain experiments other $V$. fetus strains were used, particularly in assessing the methods for the preparation of wall and flagellar material. The sources and classification of strains used are listed in Table 1. These 
smooth strains of $V$. fetus were grown in Manclark \& Pickett's (1960) liquid culture media in $500 \mathrm{ml}$. nepheloculture flasks (Ellinghausen, 1960) at a temperature of $37^{\circ}$ on a rotary shaker at $60 \mathrm{rev} . / \mathrm{min}$. Nephelometric turbidity readings of cultures (Ellinghausen, 1960) were made periodically during incubation, and organisms were harvested near the end of the logarithmic phase of growth (usually $18 \mathrm{hr}$ ) by centrifugation at $4000 \mathrm{~g}$. The organisms were washed twice by centrifugation in $0.58 \%(\mathrm{w} / \mathrm{v})$ sodium chloride and finally resuspended at about $50 \%$ ( wet $\mathrm{w} / \mathrm{v}$ ) concentration in distilled water.

\begin{tabular}{|c|c|c|c|}
\hline $\begin{array}{c}\text { Strain } \\
\text { no. }\end{array}$ & Source & Biotype* & Serotype $\uparrow$ \\
\hline 436 & Bovine foetus & $\mathbf{2}$ & $\mathbf{5}$ \\
\hline 675 & Bovine gallbladder & - & 1 \\
\hline 671 & Bovine vagina & 1 & 3 \\
\hline 652 & Ovine foetus & 2 & 1 \\
\hline 653 & Ovine foetus & 2 & 5 \\
\hline 482 & Bovine vagina & Subtype I & 3,5 \\
\hline
\end{tabular}

Preparative and separation methods. Ultrasonic treatment of whole organisms or other samples was done in an MSE Ultrasonic Oscillator operating at an output of $1.2 \mathrm{~A}$ with a sample concentration of $15 \%$ (wet $\mathrm{w} / \mathrm{v}$ ) and a volume of $15 \mathrm{ml}$. Organisms were subjected to lysozyme treatment by two different methods: that of Gilby, Few \& McQuillen (1958) and that of Repaske (1956). Of the two methods, only that of Repaske (1956) effected cell lysis. Organisms were also ruptured by shaking $10 \mathrm{ml}$. of a $10 \%$ (wet w/v) suspension of organisms with $4 \mathrm{~g}$. no. 12 Ballotoni beads for $10 \mathrm{~min}$. in a shaking machine (Mickle, 1948), and by subjecting a cell paste of $\sim 50 \%$ to pressure in the Hughes (1951) press with the piston being driven completely down. Incubation of a $2 \%$ suspension of organisms in 2-6\% sodium dodecyl sulphate was also used to produce lysis.

For the recovery of wall material after lysis or rupture of organisms, the following differential centrifugation technique was used. The suspension of broken organisms was diluted to an equivalent whole-organism concentration of 5-10\% (wet w/v). After dispersion of the material with a Pasteur pipette, it was centrifuged at $\mathbf{4 0 0 0} \mathbf{g}$ for $15 \mathrm{~min}$. to sediment unbroken organisms. (With most Hughes press preparations, a 2-3 sec. ultrasonic treatment was necessary since the material was not adequately dispersed by using the pipette). The pellet was resuspended in distilled water and again centrifuged. Both supernatant fluids were pooled; this pool represented wall and intracellular material. Centrifugation at $10,000 \mathrm{~g}$ for $30 \mathrm{~min}$. sedimented the wall material. The wall pellet was washed twice by resuspension and centrifugation, at $3000 \mathrm{~g}$ for $15 \mathrm{~min}$. and at $10,000 \mathrm{~g}$ for $30 \mathrm{~min}$., to remove residual unbroken organisms and intracellular material and to provide the crude wall material.

Flagella were prepared routinely by shaking $10 \mathrm{ml}$. of a $10 \%$ wet $(\mathrm{w} / \mathrm{v})$ suspension of organisms in water $+4 \mathrm{~g}$. Ballotini beads in a Mickle shaker for $3 \mathrm{~min}$. The yield and integrity of flagella were estimated by electron microscopy after shaking for 
various times with and without beads. Flagella were recovered by differential centrifugation in the following way. After dilution to a concentration of $1-5 \%(w / v)$ and dispersion, the material was centrifuged at $15,000 \mathrm{~g}$ for $30 \mathrm{~min}$. to sediment unbroken organisms and broken cell debris. The supernatant fluid, containing flagella, was then centrifuged at $68,000 \mathrm{~g}$ for $1 \mathrm{hr}$ to sediment the flagella. The pellet of flagella was washed twice at $15,000 \mathrm{~g}$ and at $68,000 \mathrm{~g}$ to provide the crude flagellar material. This material was then disaggregated by incubation for $1 \mathrm{hr}$ at $58^{\circ}$ in $8 \mathrm{M}$-urea solution. Disaggregated material was subjected to acrylamide gel electrophoresis by the technique of Raymond (1962).

Chemical and enzymic treatment of wall preparations for microscopy. In addition to examining crude wall material by electron microscopy, various chemically and enzymically altered wall preparations were examined. Samples $(100 \mathrm{mg}$.) of crude wall material were subjected to degradation by trypsin + RNAse + pepsin (TRP) after the method of Cummins \& Harris (1956), but were incubated for $48 \mathrm{hr}$. The wall material was examined after sedimentation at $15,000 \mathrm{~g}$ and washing twice in water.

Samples (30 mg.) were degraded by incubation at $45^{\circ}$ in the presence of $10 \mathrm{mg}$. pronase (Calbiochem, Catalog no. 53702) in $20 \mathrm{ml}$. $0.03 \mathrm{M}$-sodium phosphate buffer $(\mathrm{pH} 7 \cdot 0)$ for $1 \mathrm{hr}$ (referred to as short-term treatment) and for $6 \mathrm{hr}$ (referred to as long-term treatment). The wall material was examined by microscopy after sedimentation at $15,000 \mathrm{~g}$ and washing twice in water.

Samples $(30 \mathrm{mg}$.) of crude wall material were incubated for $10 \mathrm{~min}$. at room temperature in the presence of $5 \%(\mathrm{w} / \mathrm{v})$ sodium dodecyl sulphate in $20 \mathrm{ml}$. of $0.85 \%(\mathrm{w} / \mathrm{v}) \mathrm{NaCl}$. Again the resultant wall material was examined by electron microscopy after sedimentation and washing.

Since the lysozyme treatment conditions of Gilby et al. (1958) did not produce lysis of intact organisms, samples $(30 \mathrm{mg}$.) of crude wall material were incubated with lysozyme only after the method prescribed for whole organisms by Repaske (1956). The lysozyme-treated wall material was recovered by sedimentation without the usual washings. Similar amounts of crude wall material were extracted with $1 \%$ conc. $\mathrm{HCl}$. in water, $1 \%(\mathrm{w} / \mathrm{v}) \mathrm{NaOH}$, and $1 \%(\mathrm{w} / \mathrm{v})$, ammonium acetate and the resulting extracted wall material sedimented and washed as above before microscopic examination.

Electron microscopy. Negative staining was done with $1 \%(\mathrm{w} / \mathrm{v})$ neutral potassium phosphotungstate (PTA). Grid mounts were generally prepared by the loop-film technique described by Murray (1963). Palladium was used for metal shadowing. Materials prepared for thin-section examination were fixed with buffered ( $\mathrm{pH} \mathrm{6.5}$ ) osmium tetroxide, dehydrated in ethanol and embedded in divinylbenzene crosslinked methacrylates as described by Kushida (1961). Sections were post-stained with alkalinized lead solutions. Otherwise the methods for microscopy were as described in the accompanying paper by Ritchie, Keeler \& Bryner (1966).

Characterization methods. Spectroscopic examination of wall and intracellular preparations in the ultraviolet (u.v.) and visible regions was made with a Beckman DB spectrophotometer whose output was fed to a Photovolt Model 43 recorder. The 260 and $280 \mathrm{~m} \mu$ readings from these spectra, by using the method of calculation of Warburg \& Christian (1941), gave an estimation of the protein/nucleic acid ratio, and the absorption in the Soret region a measure of the relative cytochrome concentration of various samples. 
Cell-wall material and intracellular material to be subjected to paper chromatographic amino acid analysis were hydrolysed in $6 \mathrm{~N}-\mathrm{HCl}$ for $8 \mathrm{hr}$ at $120^{\circ}$ in sealed tubes. Hydrolysates were chromatographed two-dimensionally on $18 \mathrm{in}$. by $24 \mathrm{in}$. sheets of Whatman no. 1 paper in $n$-butanol + acetic acid + water $(120+30+50$, by vol.) and in phenol + borate buffer $\mathrm{pH} 9 \cdot 3(25+7, \mathrm{w}+\mathrm{v})$ essentially as described by Levy \& Chung (1953), but without the preliminary spray step. Amino acids were located by spraying the papers with ninhydrin $(0 \cdot 1 \%, \mathrm{w} / \mathrm{v})$ in acetone.

Cell-wall preparations to be subjected to paper chromatographic analysis for sugars were hydrolysed for $\mathbf{2 4} \mathrm{hr}$ at $120^{\circ}$ in the presence of Permutit Q (Glegg \& Eidinger, 1954) in sealed tubes. Hydrolysates were chromatographed by the descending method on Whatman no. 1 paper in ethyl acetate + pyridine + water $(120+50+40$, by vol.) and the sugars made visible by the silver nitrate spray reagent (Smith, 1960).

Cell-wall preparations were assayed for hexose by the orcinol method (Winzler, $1955 a$ ), for hexosamine by the acetylacetone Ehrlich method (Winzler, 1955b), for pentose by the aniline $\mathrm{HCl}$ method (Dische, 1962), for protein by measurement of Kjeldahl nitrogen (Kabat \& Mayer, 1961) and multiplication of the result by $6 \cdot 25$, and for total lipid by the method of Salton (1953) with an initial $2 \mathrm{hr}$ hydrolysis with $6 \mathrm{~N}-\mathrm{HCl}$ at $100^{\circ}$ followed by ether extraction to remove lipid. Wall preparations were extracted in the manner described by Baddiley, Buchanan, Rajbhandary \& Sanderson (1962) for preparation of teichoic acid.

\section{RESULTS}

\section{Susceptibility to rupture}

Vibrio fetus, strain 436, was subjected to various conditions reported to produce cellular breakage and the efficiency of breakage and relative structural integrity of the resultant wall material was assessed. When suspensions of organisms were subjected to ultrasonic treatment, they were ruptured at a rapid rate as judged by the extinction at $650 \mathrm{~m} \mu$ (Fig. 1). Microscopic examination suggested that there was greater than $90 \%$ breakage at $8 \mathrm{~min}$. of treatment and that the recognizable wall fragments were largely less than one-tenth the size of whole organisms. The yield of wall fragments appeared to be very low ( $<10 \%$ of theoretical) because of the comminution of larger pieces.

When organisms were subjected to two different methods of lysozyme treatment, results were obtained of the type shown in Fig. 2. The Repaske method (1956), method B in Fig. 2, produced rather efficient breakage since the resulting spheroplasts quickly lysed under the osmotic conditions of the experiments. The Gilby et al. (1958) method used was ineffective (method A, Fig. 2). It was found that the spheroplasts could be stabilized somewhat during lysis when incubation occurred in the presence of $\mathrm{NaCl}$ or glycerol at a final concentration of $8 \%(\mathrm{w} / \mathrm{v})$.

Treatment of suspensions of organisms with up to $10 \%$ (w/v) Tween 80 did not produce lysis. Treatment of suspensions with 2-6\% (w/v) sodium dodecyl sulphate, on the other hand, did cause lysis; but some difficulty was encountered in separating by differential centrifugation walls, cytoplasmic debris and residual sodium dodecyl sulphate.

The most promising methods of rupture tested were shaking with glass beads in 
a Mickle shaker or use of the Hughes press; both methods were capable of producing up to $95 \%$ breakage. Of the two, the Hughes press offered the most promise for breaking Vibrio fetus from the standpoint of providing intact wall fragments, although it was somewhat less desirable from the standpoint of ease of operation. The Hughes press method was selected as the method of choice for routine preparations of wall material.

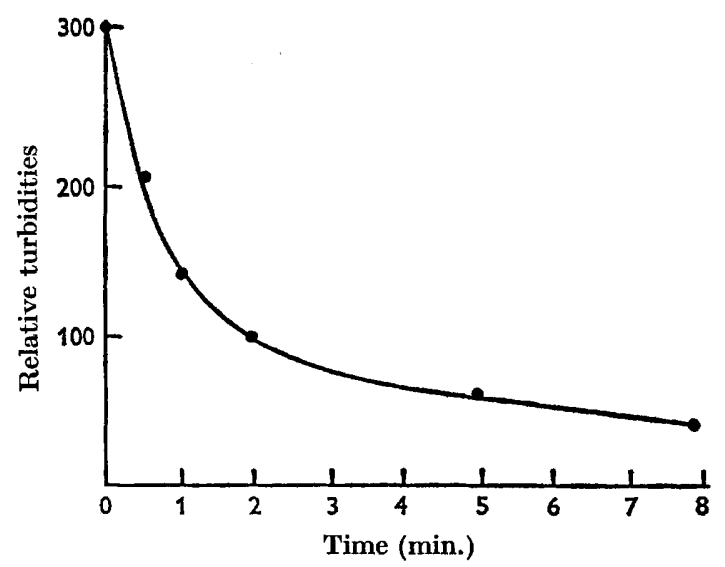

Fig. 1

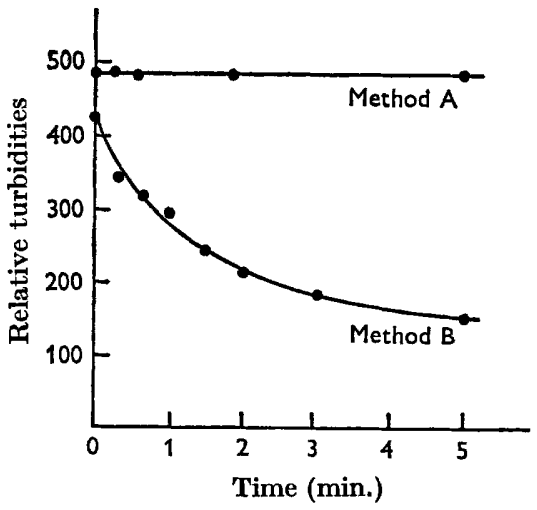

Fig. 2

Fig. 1. Rupture of Vibrio fetus, strain 436, by ultrasonic treatment (relative decrease in extinction at $650 \mathrm{~m} \mu$ as a function of time of treatment).

Fig. 2. Lysozyme lysis of Vibrio fetus, strain 436, by the methods of Gilbey et al. (1958; method A), and of Repaske (1956; method B) showing the degree of lysis (extinction at $700 \mathrm{~m} \mu$ ) as a function of time.

\section{Preparation of cell-wall material}

Cell-wall material was readily prepared by the Hughes press method from six Vibrio fetus strains in good yield. It was evident in each case that the preparation consisted of more than one structural component (Pl. 1).

The advantage of using negative staining in electron microscopic examination of the wall preparations for purity can be seen by comparing Pl. 1, fig. 5, with Pl. 2, fig. 7. Both represent wall material prepared in identical fashion from the same strain of Vibrio fetus, no. 436. Note the added detail about the presence of multilayers provided by the negatively stained preparation. The identity of the various layers will be considered below. At this point we call attention to the fact that multiple layers were seen in the $V$. fetus surface material (see Ritchie et al. 1966; and Pl. 2, fig. 8 as an example). The wall is seen as two electron-dense bands separated by a less dense band of equal thickness, the 'classical' cytoplasmic membrane as a double electron-dense band separated by a single band of lesser density, and underlying this is seen a bar-like array similar to the polar membrane in Spirillum serpens reported by Murray \& Birch-Andersen (1963). In places the two dense bands of the wall appeared as three; this may have been due to sectioning artifacts. 


\section{Preparation and nature of flagella}

Attempts were made to prepare flagella from Vibrio fetus, strain 436, by several techniques. These included shaking in the Mickle shaker, with and without no. 12 Ballotini beads for various periods of time and at various concentrations, and shaking on a wrist-action laboratory shaker under various conditions. The only technique found promising was shaking in the Mickle shaker with Ballotini beads. Plate 3, figs. 9-11, show the results when organisms were shaken for various periods of time (10 ml. of a $10 \%, \mathrm{w} / \mathrm{v}$, suspension of organisms in water $+4 \mathrm{~g}$. beads). It is evident that the $3 \mathrm{~min}$. shake provided flagella in the best state of preservation and most free from contaminating wall fragments. Differential centrifugation was used in all cases to separate the flagella from other cellular debris. By the $3 \mathrm{~min}$. shake treatment and the differential centrifugation purification method, flagella were prepared from all the $V$. fetus strains under investigation except strain 652 .

Flagella preparations from most strains were found on occasion to be contaminated with spherical bodies of about 300-800 $\AA$ diameter whose origin was not known. This contaminant was best made visible in negatively stained preparations (Pl. 3, fig. 12). It is interesting to note that the 'blebs' seen frequently on the surface of whole vibrios (Pl. 3, fig. 13) were of a size distribution (250-400 $\AA$. diam.) similar to the smallest of the spherical bodies seen in the flagella preparations. However, either may have arisen as artifacts during the course of drying with phosphotungstate (Chance \& Parsons, 1963), although blebs are often revealed in thin section when no phosphotungstate has been used. Urea disaggregation of flagella preparations containing spheres showed as many as four separate protein bands when submitted to acrylamide gel electrophoresis, while preparations free from spheres showed three bands. A detailed description of the chemical characterization of the flagella will be published later.

\section{Characterization of wall preparations}

The crude wall material was subjected to several chemical tests to help characterize it and to determine whether it was free from intracellular material and cytoplasmic membrane. All wall and intracellular preparations were examined by visible and ultraviolet spectra for evidence of absorption in the Soret region due to cytochrome (cytoplasmic membrane; Keeler, Carr \& Varner, 1958; Keeler \& Gray, 1960) or at $260 \mathrm{~m} \mu$ due to the presence of nucleic acid (intracellular material). Figure 3, which shows data for Vibrio fetus, strain 436 , and is typical of all preparations, shows the results. The wall material from all strains had only a trace of an absorption peak in the Soret region (near $400 \mathrm{~m} \mu$ ) and at $260 \mathrm{~m} \mu$, while the intracellular material possessed peaks at 410 and $260 \mathrm{~m} \mu$. Because of general light scatter in the visible range, a concentration of wall material of only about one-eighth that of intracellular material was used, thus increasing the significance of the Soret absorption of the wall preparation. From these results the crude wall material was thought to be significantly contaminated with cytoplasmic membrane but to be relatively free from intracellular material. Table 2 indicates the ratio of protein to nucleic acid in these materials.

Wall and intracellular preparations from each of the strains of Vibrio fetus were hydrolysed and the hydrolysates subjected to two-dimensional amino acid chromato- 
graphy. The results showed that there was a similar qualitative and semi-quantitative distribution of amino acids in all samples from all strains, whether of wall material or intracellular material. There were 21 ninhydrin-positive spots, 15 being identified as amino acids. Figure 4 is a diagram of the distribution of identified and unidentified spots (the latter are doubly circled). Total hexose, hexosamine, pentose, protein and lipid were determined on all crude wall preparations. The average contents in crude wall material from all six strains were: hexose, $14.9 \pm$

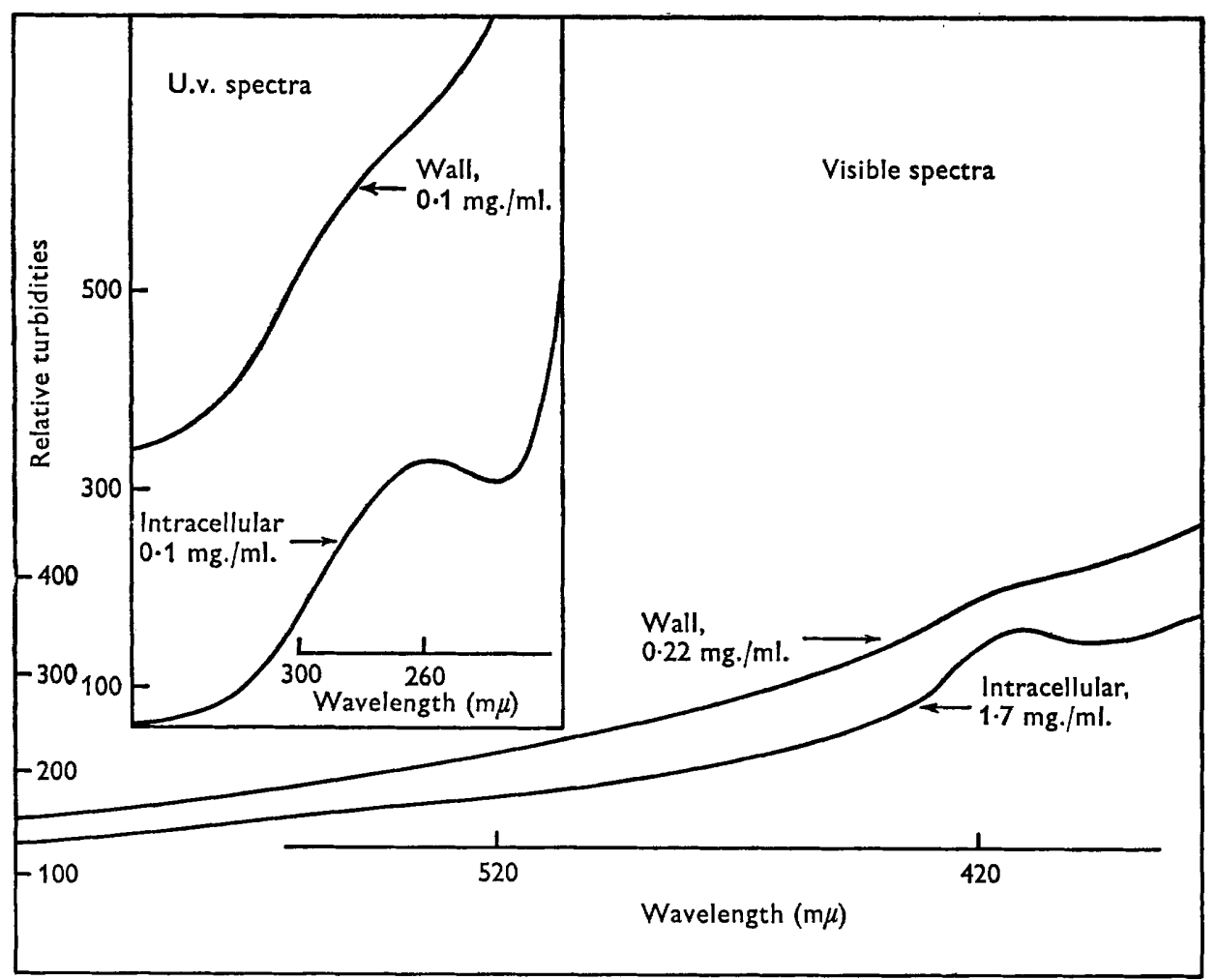

Fig. 3. Visible and ultraviolet absorption spectra of wall and intracellular material from Vibrio fetus, strain 436.

Table 2. Ratio of protein to nucleic acid concentration in wall and intracellular preparations from Vibrio fetus strains*

$\begin{array}{ccc}\text { Strain no. } & \text { Wall } & \begin{array}{c}\text { Intracellular } \\ \text { material }\end{array} \\ 436 & 15 \cdot 0 & 5 \cdot 6 \\ 675 & 17 \cdot 0 & 9 \cdot 0 \\ 671 & 17 \cdot 0 & 10 \cdot 0 \\ 652 & 20 \cdot 0 & 6 \cdot 2 \\ 653 & 17 \cdot 0 & 5 \cdot 6 \\ 482 & 17 \cdot 0 & 5 \cdot 8 \\ \text { Average } & 17 \cdot 2 & \mathbf{7 \cdot 0}\end{array}$

* Calculated from $260 \mathrm{~m} \mu / 280 \mathrm{~m} \mu$ absorbancies by the method of Warburg \& Christian (1941). 
$1.9 \%$, hexosamine $0.59 \pm 0 \cdot 18 \%$, pentose $0 \cdot 10 \pm 0.03 \%$, protein (calculated from Kjeldahl-nitrogen) $65 \cdot 1 \pm 6 \cdot 0 \%$, lipid 16.9. The standard deviations indicated close similarity between all six strains. Using these average figures, $97 \cdot 6 \%$ of the crude wall material was accounted for.

The sugars in the crude wall preparations were found by chromatography of hydrolysates to be composed of over $80 \%$ glucose with small amounts of what appeared to be arabinose and xylose, plus two or three other unidentified spots. There was some variability from strain to strain, and a more critical examination of the sugar composition by the methods of Salton (1961) to check for strain differences seems warranted.

The wall material of Vibrio fetus is fragile and undergoes comminution to small particles rapidly with ultrasonic treatment (Pl. 4). This fragility discouraged the use of ultrasonic treatment in preparation of $V$. fetus wall material or as a technique for dispersing wall preparations for electron microscopy.

Table 3. Comparison of the relative amino acid composition of untreated control, TRP-treated and pronase-treated wall material from Vibrio fetus strain 436

$\begin{array}{lccc}\text { Amino acid } & \begin{array}{c}\text { TRP- } \\ \text { treated }\end{array} & \begin{array}{c}\text { Pronase- } \\ \text { treated }\end{array} & \begin{array}{c}\text { Untreated } \\ \text { control }\end{array} \\ \text { Ala } & +++ & ++++ & ++++ \\ \text { Lys } & +++ & ++ & ++ \\ \text { Gly } & ++ & ++ & ++ \\ \text { Glu } & ++ & +++ & +++ \\ \text { Asp } & ++ & +++ & +++ \\ \text { Cys (or DAP ?) } & + & + & + \\ \text { Val-Meth } & \text { Trace } & ++ & +++ \\ \text { Arg } & \text { Trace } & + & + \\ \text { Ser } & \text { Trace } & +++ & +++ \\ \text { Thr } & \text { Trace } & +++ & +++ \\ \text { Hist } & - & + & + \\ \text { Tyro } & - & + & ++ \\ \text { Pro } & - & + & + \\ \text { Oala-isoleu-leu } & - & +++ & ++++ \\ \text { Unknown 1 } & - & - & + \\ \text { Unknown 2 } & - & - & + \\ \text { Unknown 3 } & - & + & + \\ \text { Unknown 4 } & - & - & + \\ \text { Unknown 5 } & - & & + \\ \text { Unknown 6 } & - & & +\end{array}$

Crude wall material from Vibrio fetus, strain 436, was subjected to a variety of chemical extractions and enzymic degradations in an effort to decrease its complexity and to establish the identity and composition of various wall layers. Wall preparations incubated with TRP, pronase, or lysozyme are shown in Pl. 5, figs. 17-19, respectively. Wall preparations extracted with either sodium dodecyl sulphate or phenol are shown in Pl. 5, figs. 20, 21 respectively. The photographs of Pl. 5 show a very evident change (degradation) of wall material in each case. Amino acid analyses of hydrolysates of the residual wall fragments of the TRP-, pronase-, and non-treated control material are shown in Table 3. The residual wall after TRP treatment appeared to be changed to a material with an amino acid composition similar to wall mucopeptide (Salton, 1960), while pronase treatment, with the 
exception of the unknown spots, appeared to attack the amino acids of both wall protein and mucopeptide non-preferentially, since the relative concentrations of the appropriate amino acids change but little.

Of considerable interest to us was the relative rigidity, evidenced by the general shape or maintenance of an elongated structure, of the residual wall fragments after various treatments. In no case did the residual wall fragments retain the elongated rigidity of the large fragments of the crude untreated wall preparation ( $\mathrm{Pl}$. 4, fig. 14). Considerable loss of cell-wall rigidity occurred (Pl. 5, figs. 17-21) with the TRP treatment, while somewhat less occurred with the treatments with sodium dodecyl sulphate, lysozyme or pronase. The phenol treatment apparently produced substantial loss of rigidity, but it was difficult to assess because of agglomeration of wall fragments. There were evident small round objects of unknown nature, with an appearance suggestive of balls of twine (Pl. 5, fig. 17, arrow $\mathbf{A}$ ) and distributed amongst the TRP-treated wall fragments with a high degree of regularity. In the lysozyme-treated walls the background was extensively covered with small irregularshaped fragments (Pl. 5, fig. 19, arrow B).

When pronase digestion of crude wall material was discontinued after a short time, wall residues of appearance considerably different from those of $\mathrm{Pl}$. 5, fig. 18, were evident. The fragments retained their elongated rigidity and suffered a preferential loss of internal sacs (Pl. 6). The arrow markers (A) in Pl. 6, indicate a stringy structure frequently seen in short pronase treatment. The stringy material (A) which was in close proximity to the periphery might have arisen from one of the wall layers (see description of endotoxin below). The discrete internal structures which appear as internal sacs or hemispheres (B) may have been the bar-like array, while the cytoplasmic membrane was probably the shaded area (CM) directly beneath the cell wall (CW). Alternatively, these internal sacs and hemispheres might be cytoplasmic membrane whose protein has been partially degraded by the pronase and whose lipid content is therefore proportionally higher, allowing an agglomeration into smaller spherical lipid artifact bodies. Those spherical forms lying external to recognizable whole cell walls are thought to have arisen by the latter process.

Plate 5, fig. 21, shows the appearance of residual wall material in the phenol phase of phenol-extracted wall preparations. When the pooled interface and aqueous phase were examined, there was evident long stringy material (Pl. 7, figs. 26, 27) labelled with arrow markers (A). This stringy material comprised a large proportion of the visible mass of the fraction. Nearly all the remaining visible mass was accounted for by round or otherwise smooth edged material (labelled B) which frequently was intimately attached to the end of one of the stringy fibres as though one were giving rise to the other. The stringy material was thought to be the lipopolysaccharide (endotoxin) of the wall on the basis of its almost identical appearance ('long intertwined sausages') and mode of preparation with that described by Weidel et al. (1960) from Escherichia coli. It was also quite similar to that shown by Milner et al. (1963), for some bordetella species especially the 'threadlike structures formed from otherwise amorphous endotoxin' due to drying. Perhaps the stringy material shown in Pl. 6 was also lipopolysaccharide.

When TRP-treated wall residues of Vibro fetus, strain 436, were subsequently treated with sodium dodecyl sulphate, a decrease in the turbidity of the suspension was noted (Fig. 5), similar to that reported for other Gram-negative organisms by 
Shafa \& Salton (1960) who concluded that the treatment produced a disaggregation of wall. That this treatment did not produce disaggregation in $V$. fetus walls, even though the turbidity decrease might suggest it did, was supported by the following observations. The decrease in turbidity was accompanied by formation of floccules which settled to the bottom of the cuvette in which the extinction measurements were being made and the turbidity was regained upon dialysis to remove sodium

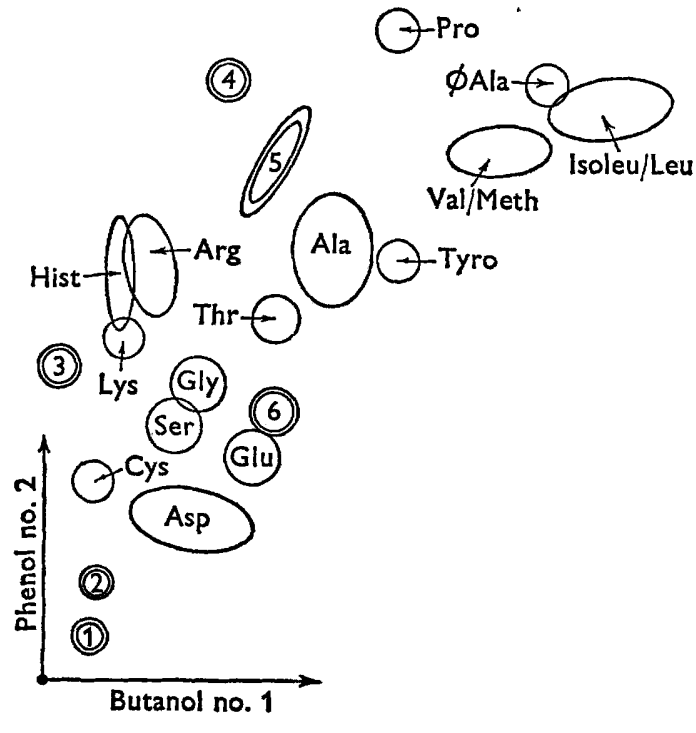

Fig. 4

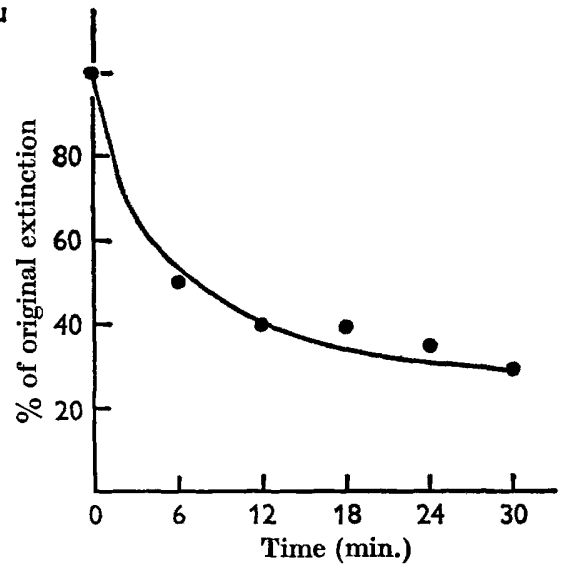

Fig. 5

Fig. 4. Diagram of ninhydrin-positive spots in hydrolysates. Both wall and intracellular material hydrolysates from all six strains of Vibrio fetus gave results of this type: the same spots at about the same concentrations.

Fig. 5. Change in extinction at $700 \mathrm{~m} \mu$ of a suspension of TRP-treated cell wall residues from Vibrio fetus, strain 436 , when incubated in $0.2 \%$ sodium dodecyl sulphate.

dodecyl sulphate. Lastly, residual walls were readily observed by electron microscopy in the treated preparation after dialysis, although they tended to agglomerate. The amino acid composition of hydrolysates of the sodium dodecyl sulphatetreated crude wall material appeared in preliminary experiments to be similar to that of the TRP-treated wall material in possessing only those amino acids expected in the wall mucopeptide layer.

It has not been possible to resolve any substructure in the surface layers of Vibrio fetus, such as the tightly packed spheres of Escherichia coli (Weidel et al. 1960) or the hexagonally structured array of Spirillum serpens (Murray, 1963). This was true whether $V \cdot$ fetus wall material was untreated or treated with any of the reagents described above or with $1 \%$ conc. $\mathrm{HCl}$ in water, $1 \% \mathrm{NaOH}$, or $1 \%$ ammonium acetate. The ordered array of surface spheres of $E$. coli have been found (unpublished results) in negatively stained mounts of whole organisms prepared in an identical manner as for the $V$.fetus organisms used in this work. Thus $V$. fetus more closely resembles Salmonella gallinarum (Weidel, Frank \& Leutgeb, 1963) in 
this respect than either $\boldsymbol{E}$. coli or $\boldsymbol{S}$. serpens, both of which are well endowed with visible structure in the mucopeptide layer and the untreated whole wall, respectively.

The wall preparation of Vibrio fetus, strain 436, was embedded and subjected to thin sectioning; Pl. 8 shows representative fields of the sectioned material. A few organisms have largely retained their cytoplasmic contents. Cell wall $(\mathrm{CW})$ and cytoplasmic membrane (CM) are visible-both retaining to a large degree their double electron-dense layering. The structural layers are best resolved near the point of flagellar attachment. The bar-like array (LS) was not well resolved. Only a hint of its presence was evident as a density change in the subcytoplasmic membrane area, where it would be expected. No internal membranes or vesicles of the type found in Azotobacter by Pangborn, Marr \& Robrish (1962) or in Micrococcus by Lukoinova, Gelman \& Biriusova (1961) were found in $V$. fetus.

By using standard methods of extraction (Baddiley et al. 1962), we found no teichoic acid, common to Gram-positive organisms, present in the wall preparations of the Gram-negative Vibrio fetus. A description of the antigenic composition, the cross reactivity among strains, the cytologic origin of antigens, and the chemical and physical characterization of various preparations described herein will be reported later. We simply note in brief here that there can be obtained from the aqueous phenol phase of the phenol extract of whole organisms material which is antigenic and possesses toxic and pyrogenic activity in mice and rabbits. Further, there appear to be at least two antigens in the cell wall which are not similar to intracellular antigens, while the intracellular material possess at least three strong antigens not originating from wall material. Flagellar material is also antigenic.

\section{DISCUSSION}

Hunt, Rodgers \& Hughes (1959) and Hughes (1962) reported that wall material prepared by using the Hughes press contained cytoplasmic membrane as well as cell wall. This is certainly the case for Vibrio fetus. Electron microscopy of negatively stained and thin sections of wall preparations, as well as the light absorption in the Soret region (a measure of membrane cytochrome) suggest this to be so. However, unlike Hughes (1962), we did not find $V$.fetus wall prepared by breaking in a Mickle shaker to be any less contaminated with membrane material. Negative staining was of great value in assessing wall preparations for freedom from membrane material. It is likely that many shadowed wall preparations reported to be pure would not have appeared so pure if negatively stained preparations had been used for microscopy.

Regarding the question of which wall layer confers rigidity to Vibrio fetus organisms, the following points may be considered. It is usually thought that the mucopeptide layer, which may constitute less than $1 \%$ of the bacterial mass or about 3-10\% of the cell-wall fraction (Weidel et al. 1960, 1963; Mandelstam, 1962; Salton, 1961), is the structure which provides rigidity to the cell wall of Gramnegative organisms (Weidel et al. 1960; Mandelstam, 1962). The argument is that this layer must confer rigidity because lysozyme lysis of whole organisms produces osmotically fragile spheroplasts (Mandelstam, 1962). It seems apparent with $V$. fetus (as shown here) and Escherichia coli (Weidel et al. 1963) that lysozyme releases not only the mucopeptide substrate, but probably the lipopolysaccharide as well, 
each of which could therefore contribute to structural rigidity. Residual wall material after any of the treatments used here did not seem to possess exclusive claim to rigidity; each layer, it would seem, might contribute to this rigidity or, possibly more accurately stated, to the tensile strength of the wall complex.

We have tacitly assumed the outer double electron-dense region of Vibrio fetus to be the three-layered wall, and the next inner double electron-dense region to be the 'classical' cytoplasmic membrane, much as postulated by Weidel et al. (1960) for Escherichia coli B. Other explanations are possible. Clark \& Lilly (1962) interpreted their own and Weidel's data to suggest the presence in $\boldsymbol{E}$. coli of two 'unit membranes' (the cytoplasmic 'unit membrane' and the outer wall 'unit membrane') between which was found the rigid layer composed of mucopeptide and possibly teichoic acid in $E$. coli 26-26. Each 'unit membrane', it was proposed, would be composed of polysaccharide-lipid-lipid-protein with the polysaccharide layers facing the mucopeptide. Even if this were a correct interpretation for $\boldsymbol{E}$. coli, which to us seems doubtful, $V$. fetus has too much vacant space between the 2-layered cytoplasmic membrane and the outer double electron-dense wavy wall layers to be accounted for by mucopeptide. The peptide portion of the mucopeptide would be expected to take the osmium stain readily, but we see no evidence of staining in the vacant space.

In view of the presence of the bar-like array at the inner surface of the cytoplasmic membrane of Vibrio fetus, possibly comprising part of the membrane, it becomes of some interest to consider the localization of the cytochromes and other components, including enzymes, reportedly present in the cytoplasmic membrane of bacteria (Hughes, 1962; Mitchell, 1959; Keeler \& Gray, 1960; Keeler et al. 1958). The bar-like array might be involved in terminal oxidation and electron transport where the functional entities associated with these activities, including the cytochromes, might be architecturally oriented therein. Such an arrangement might account for the presence of cytochromes in membrane preparations. Of further interest would be a survey of a wide variety of organisms for the presence of a similar structure. Workers who have demonstrated the presence of internal membranes in Gram-negative bacteria (Pangborn et al. 1962; Lukoinova et al. 1961) have postulated that these intra-cytoplasmic membranes are the sites of various respiratory enzymes. It might be revealing to compare functional similarities of the morphologically different intra-cytoplasmic membranes and the bar-like array.

Murray \& Birch-Andersen (1963) postulated a specialized function in Spirillum for the bar-like array which they referred to as the plasma membrane-polar membrane complex. Since they had found it to be restricted to the pole, they wondered whether it might have some relationship to the flagella, as follows: 'It is usual to look upon strictly spaced associations of membranes as having something to do with specialized energy transformations and it is consequently tempting to try and relate the plasma membrane-polar membrane complex with the liberation of energy for the flagella. It is an assumption to consider that all the observed modifications of polar structure are to do with flagella; even if we do make the assumption, it is important to point out that alternative possibilities exist. One of these is the synthesis of new cell walls, which may well go on in this region and may require considerable energy and organization.' Since we found the bar-like array not 


\section{Cell wall and flagella of Vibrio fetus}

limited to the poles in Vibrio fetus, our less restrictive hypothesis seems more appropriate.

In common with the report of Weidel and co-workers for Escherichia coli and Salmonella gallinarum (1960, 1963), treatment with sodium dodecyl sulphate of Vibrio fetus has been shown here to provide the wall mucopeptide layer in a state which appears to be essentially free from other structural elements. This is at odds with the report of Shafa \& Salton (1960) for Gram-negative organisms that sodium dodecyl sulphate completely disaggregated the walls, mucopeptide layer included. An explanation for this anomaly suggested by Weidel et al. (1963) was that the disaggregation seen by Shafa \& Salton (1960) was due to degradation by autolytic enzymes, not to disaggregation by sodium dodecyl sulphate, since in preparations properly protected from autolysis, the mucopeptide layer could be recovered after treatment with sodium dodecyl sulphate. And indeed this was the preparative method of choice for recovery of the mucopeptide layer. This does not appear to be a satisfactory explanation for the results obtained with $V$. fetus. We did see what appeared to be disaggregation on treatment with sodium dodecyl sulphate, since the extinction of the wall suspension decreased just as reported by Shafa \& Salton (1960) for certain Gram-negative organisms. With $V$. fetus, however, this was not due to disaggregation but to aggregation and subsequent settling of wall fragments; autolysis apparently played no role. The sodium dodecyl sulphate treatment of crude walls or the TRP treatment of walls, both of which produced very delicate thin wall ghosts of similar appearance, apparently yield the mucopeptide layer of the wall. Thus, sodium dodecyl sulphate appears to remove all lipopolysaccharide in $V$. fetus as it does in $S$. gallinarum (Weidel et al., 1963), both of which are contrary to the case with $\boldsymbol{E}$. coli (Weidel et al., 1960). Further, sodium dodecyl sulphate apparently removes the lipoprotein outer layer, since the amino acid composition of the insoluble wall residues is as would be expected for mucopeptide (Salton, 1960) in the absence of protein.

The micrographs of lysozyme-treated walls provide visual verification of the statement by Weidel et al. (1963) that '...upon destruction of the supporting mucopolymer layer, e.g. with lysozyme, a host of wall components will be freed, most of which are anything but lysozyme-split products'. There is evident in our lysozyme-treated Vibrio fetus preparations a large number of irregularly shaped fragments obviously released from the wall as a result of the lysozyme treatment (Pl. 5, fig 19). They are evidently not lysozyme substrate, but arise as a result of degradation of a supporting structure. We postulate that lysozyme treatment of crude walls of $V$. fetus solubilizes the mucopeptide layer and in so doing, because of the nature of its bonding to the lipopolysaccharide layer, releases the latter layer as irregularly shaped pieces or aggregates (background) and leaves intact the outer microcapsule lipoprotein layer.

\section{REFERENCES}

Baddiley, J., Buchanan, J. G., Rajbhandary, U. L. \& Sanderson, A. R. (1962). Teichoic acid from the walls of Staphylococcus aureus. II. Structure of the N-acetylglucosaminylribitol residues. Biochem. J. 82, 439.

Bryner, J. H., Frank, A. H. \& O'Berry, P. A. (1962). Dissociation studies of Vibrios from the bovine genital tract. Am. J. Vet. Res. 23, 32. 
Chance, B. \& Parsons, D. F. (1963). Cytochrome function in relation of inner membrane structure of mitochondria. Science, 142, 1176.

Clark, P. H. \& Lilly, M. D. (1962). A general structure for cell walls of Gram-negative bacteria. Nature, Lond. 195, 516.

Cummins, C. S. \& Harris, H. (1956). The chemical composition of the cell wall in some Gram-positive bacteria and its possible value as a taxonomic character. J. gen. Microbiol. 14, 583.

Dische, Z. (1962). Color reactions of pentoses. Meth. carbohyd. Chem. 1, 484.

Ellinghausen, H. C. (1960). Some observations on cultural and biochemical characteristics of L. pomona. J. infect. Dis. 106, 237.

Gilby, A. R., Few, A. V., \& McQuillen, K. (1958). The chemical composition of the protoplast membrane of Micrococcus lysodeikticus. Biochim. biophys. Acta, 29, 21.

GlegG, R. E. \& Eidinger, D. (1954). Hydrolysis of polysaccharide by a cation exchange resin and identification of monosaccharide components by paper chromatography. Anal. Chem. 26, 1365.

Hughes, D. E. (1951). A press for disrupting bacteria and other micro-organisms. $B r . J$. exp. Path. 32, 97.

Hughes, D. E. (1962). The bacterial cytoplasmic membrane. J. gen. Microbiol. $29,39$.

Hunt, A. L., Rongers, A. \& Hughes, D. E. (1959). Subcellular particles and the nicotinic hydroxylase system in extracts of Ps. fluorescens. Biochem. biophys. Acta, 34, 354.

Kabat, E. A. \& MAYER, M. M. (1961). Experimental Immunochemistry, p. 476. Springfield, Illinois: Charles C. Thomas.

Keeler, R. F. \& Gray, M. L. (1960). Antigenic and related biochemical properties of Listeria monocytogenes. I. Preparation and composition of cell wall material. $\boldsymbol{J}$. Bact. 80, 683.

Kaeler, R. F., Carr, L. B. \& VARner, J. E. (1958). Intracellular localization of iron, calcium, molybdenum, and tungsten in Azotobacter vinelandii. Exp. Cell Res. 15, 80.

Kushida, H. (1961). A new embedding method for ultrathin sectioning using a methacrylate resin with three dimensional polymer structure. J. electron Microsc. 10, 194.

Leifson, E. (1960). Atlas of Bacterial Flagellation. New York: Academic Press.

LEvy, A. L. \& ChUNG, D. (1953). Two-dimensional chromatography of amino acids on buffered papers. Anal. Chem. 25, 396.

Lukoinova, M. A., Gelman, N. S. \& Biriusova, V. I. (1961). Structure of cytoplasmic membranes of Micrococcus lysodeikticus with reference to succinic oxidase and succinic dehydrogenase activity. Biokhimiya, 26, 916.

Manclark, C. R. \& Pickett, M. (1960). Quantitative production of Vibrio fetus cells. $J$. Bact. 79, 752.

Mandelstam, J. (1962). Preparation and properties of the mucopeptides of cell walls of Gram-negative bacteria. Biochem. J. 84, 294.

Marsh, H. \& Firehammer, B. D. (1953). Serological relationships of twenty-three ovine and three bovine strains of Vibrio fetus. Am. J. Vet. Res. 14, 396.

Mickle, H. (1948). Tissue disintegrator. J. R. micro. Soc. 68, 10.

Milner, K. C., Anacker, R. L., Fukushi, K., Hoskins, W. T., Landy, M., Malugren, $B$. \& RIBI, E. (1963). Symposium on relationship of structure of microorganisms to their immunological properties. III. Structure and biological properties of surface antigens from Gram-negative bacteria. Bact. Rev. 27, 352.

Mrtcheld, P. (1959). Biochemical cytology of micro-organisms. Ann. Rev. Microbiol. 13, 407.

Murray, R. G. E. (1963). On the cell wall structure of Spirillum serpens. Can. J. Microbiol. 9, 381.

Murray, R. G. E. \& Birch-Andersen, A. (1963). Specialized structure in the region of the flagella tuft in Spirillum serpens. Can. J. Microbiol. 9, 393.

Pangborn, J., Marr, A. G. \& Robrish, S. A. (1962). Localization of respiratory enzymes in intracytoplasmic membranes of Azotobacter agilis. J. Bact. 84, 669.

RAYMond, S. (1962). A convenient apparatus for vertical gel electrophoresis. Clin. Chem. 8,455 . 


\section{Cell wall and flagella of Vibrio fetus}

REPASke, R. (1956). Lysis of Gram-negative bacteria by lysozyme. Biochem. biophys. Acta, 22, 189.

Ritchie, A. E., Keeler, R. F. \& Bryner, J. H. (1966). Anatomical features of Vibrio fetus: electron microscope survey. J. gen. Microbiol. 43, 427.

SALTON, M. R. J. (1953). Studies of the bacterial cell wall. IV. The composition of the cell walls of some Gram-positive and Gram-negative bacteria. Biochem. biophys. Acta, $10,512$.

Salton, M. R. J. (1960). Microbial cell realls. New York: John Wiley and Sons.

Salton, M. R. J. (1961). Studies of the bacterial cell wall. VII. Monosaccharide constituents of the walls of Gram-negative bacteria. Biochem. biophys. Acta, 45, 364.

Salton, M. R. J. (1964). The Bacterial Cell Wall. New York: Elsevier Publishing Company.

Shafa, F. \& Salton, M. R. J. (1960). Disaggregation of bacterial cell walls by anionic detergents. J. gen. Microbiol. 23, 137.

Sмгтн, I. (1960). Chromatographic and electrophoretic techniques, p. 246. New York: Interscience Publishers, Inc.

Warburg, D. \& Christian, W. (1941). Isolierung und Kristallisation des Gärungsferments Enolose. Biochem. Z. 310, 384.

Weidel, W. \& Pelzer, H. (1964). Bag shaped macromolecules. Advan. Enzymol. 26, 193.

Weidel, W., Frank, H. \& Leutgeb, W. (1963). Autolytic enzymes as a source of error in the preparation and study of Gram-negative cell walls. J. gen. Microbiol. 30, 127.

Weidel, W., Frank, H. \& Martin, H. H. (1960). The rigid layer of the cell wall of Escherichia coli strain B. J. gen. Microbiol. 22, 158.

WinzLer, R. J. (1955a). Determination of serum glycoproteins. Meth. biochem. Anal. 2, 290.

Winzler, R. J. (1955b). Determination of serum glycoproteins. Meth. biochem. Anal. 2, 292.

\section{EXPLANATION OF PLATES}

Plate 1

Cell-wall preparations from six strains of Vibrio fetus made with the Hughes press. All preparations negatively stained with PTA for microscopy. Arrow markers indicate multiple layers present in each wall preparation. Fig. 1. Strain 653. Fig. 2. Strain 482. Fig. 3. Strain 675. Fig. 4. Strain 652. Fig. 5. Strain 436. Fig. 6. Strain 671. Fig. $1=\times 31,000$. Fig. $2 .=\times 43,000$. Fig. $3=\times 62,000$. Fig. $4=\times 60,000$. Fig. $5=\times 33,000$. Fig. $6=\times 45,000)$.

\section{Plate 2}

Fig. 7. Wall preparation from Vibrio fetus, strain 436, made with the Hughes press and shadowed with palladium for microscopy. Fig. 8. Thin section of $V$. fetus, strain 436, fixed with $\mathrm{OsO}_{4}$ and stained with lead for microscopy. Note double electron-dense layers in the cell wall (CW), the double electron-dense cytoplasmic membrane (CM), the bar-like array (LS), and the flagella stub (F). (Fig. $7=\times 10,000$. Fig. $8=\times 135,000$.)

\section{Plate 3}

Figs. 9-11. Flagella prepared from Vibrio fetus, strain 436, by shaking organisms with beads for 3, 10 and 30 min., respectively, in the Mickle shaker, and then subsequent differential centrifugation for purification. All preparations were shadowed with palladium for microscopy. Fig. 12. Negatively stained (phosphotungstate) flagellar preparations from $V$. fetus, strain 671, showing a spherical, contaminant at arrow marker. Fig. 13. Negatively-stained (phosphotungstate) $V$. fetus, strain 671 . showing surface blebs at the periphery of organism at arrow marker. (Fig. $9=\times 23,000$. Fig. 10= $\times 19,000$. Fig. $11=\times 16,000$. Fig. $12=\times 54,000$. Fig. $13=\times 55,000)$.

\section{Plate 4}

Comminution of Vibrio fetus, strain 436, wall material by ultrasonic treatment. Fig. 14. No treatment. Fig. 15. 15 sec. treatment. Fig. 16. 30 sec. treatment. (Fig. 14 $=\times 51,000$. Fig. $15=\times$ 56,000. Fig. $16=\times 62,000$.) 


\section{Plate 5}

Residual wall remaining after enzymic and chemical treatment of Vibrio fetus, strain 436, wall material. Preparations negatively stained (phosphotungstate) for microscopy. Fig. 17. Incubation with TRP; note objects with the appearance of balls of twine at arrow marker. Fig. 18. Long-term incubation with pronase. Fig. 19. Incubation with lysozyme by the Repaske (1956) method; note residual irregularly shaped fragments about $1 / 20$ the size of whole walls at arrow marker. Fig. 20. Extracted with sodium dodecyl sulphate. Fig. 21. Extracted with phenol. (Fig. $17=\times 62,000$. Fig. $18=\times 45,000$. Fig. $19=47,000$. Fig. $20=\times 46,000$. Fig. $21=\times 42,000$.)

\section{Plate 6}

Figs. 22-25. Short-term incubation of wall material of Vibrio fetus, strain 436, with pronase and negatively stained with phosphotungstate. Note the stringy material (A), the residual internal hemispheres and spherical-shaped objects (B), the cell wall (CW) and the cytoplasmic membrane (CM). (Fig. $22=\times 27,000$. Fig. $23=\times 40,000$. Fig. 24 $=\times 69,000$; fig. $25=\times 57,000$.)

\section{Plate 7}

Figs. 26, 27. The stringy material of the pooled interface and aqueous layers from phenol extracted Vibrio fetus, strain 436, wall preparations at arrow marker (A); also shows the occasional presence of spherical forms (B). Negative staining with phosphotungstate. (Fig. $26=\times 155,000$. Fig. $27=\times 69,000$.)

\section{Plate 8}

Figs. 28-30. Thin sections of Vibrio fetus, strain 436, wall material fixed with $\mathrm{OsO}_{4}$ and stained with lead showing the cell wall (CW), the cytoplasmic membrane (CM), the bar-like array (LS), and flagella stub (F). (Fig. $28=\times 63,000$. Fig. $29=\times 50,000$. Fig. $30=\times 135,000$.) 

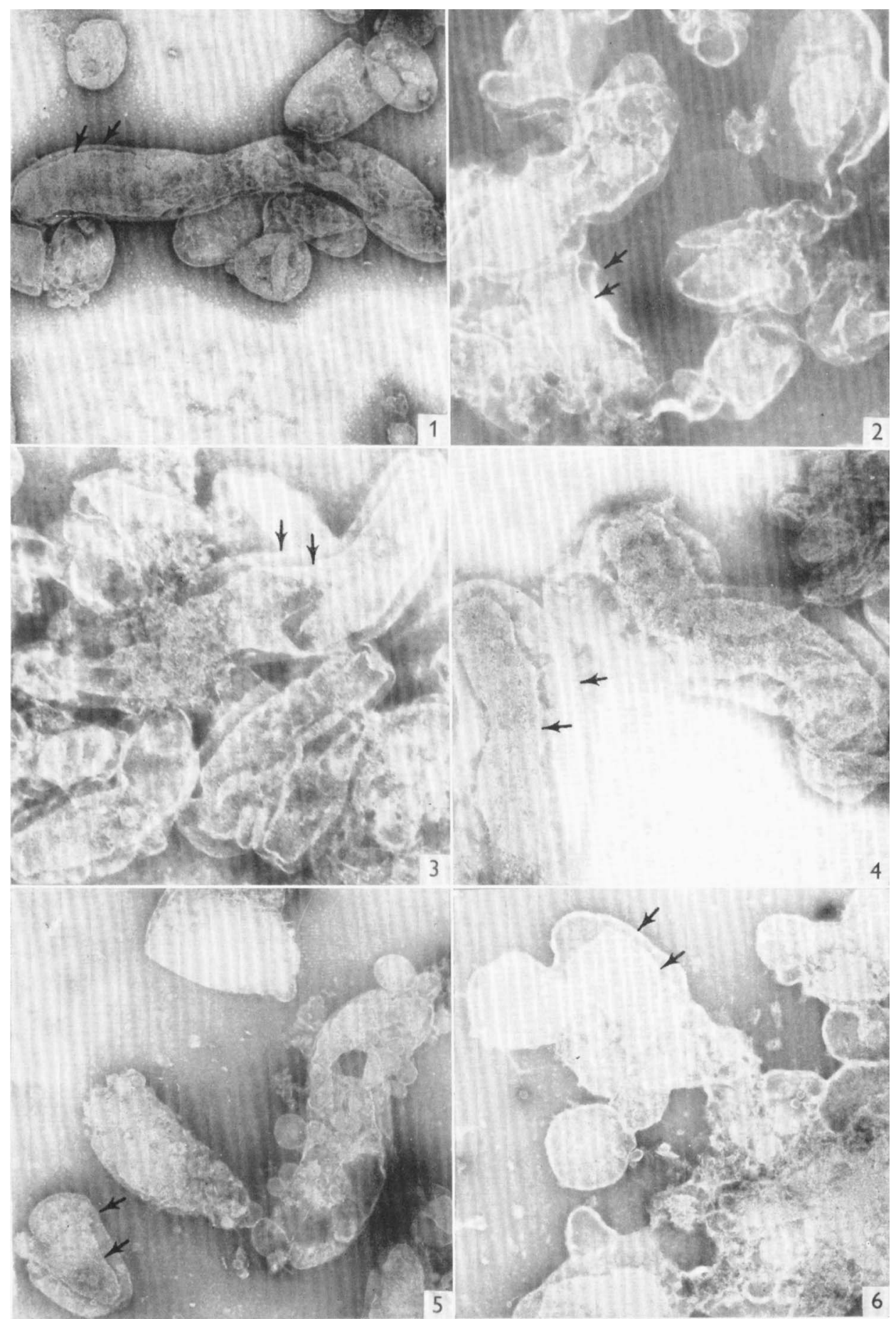

R. F. KEELER AND OTHERS

(Facing p. 454) 

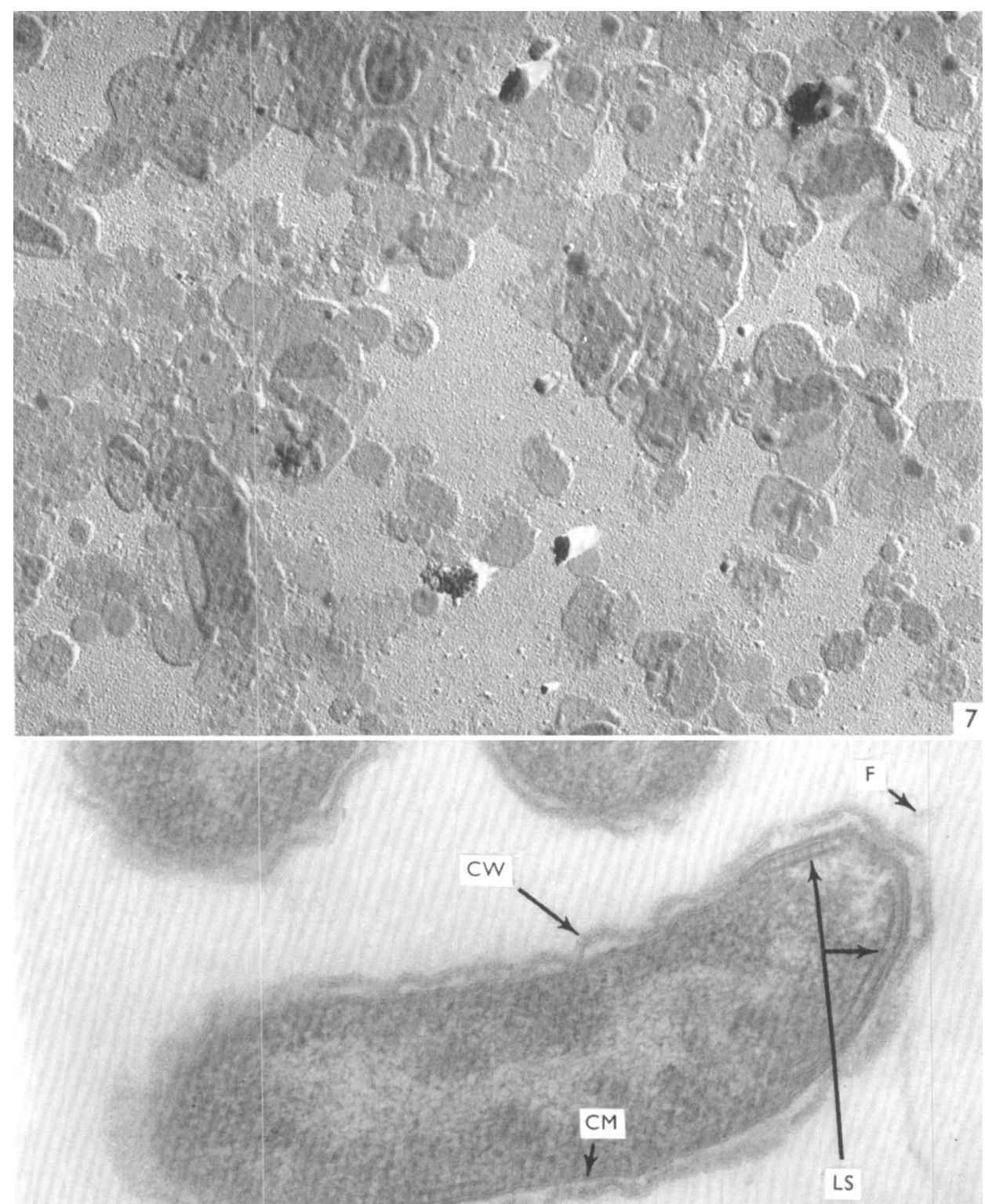

CM

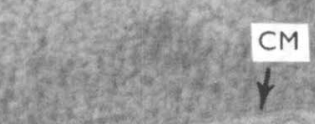



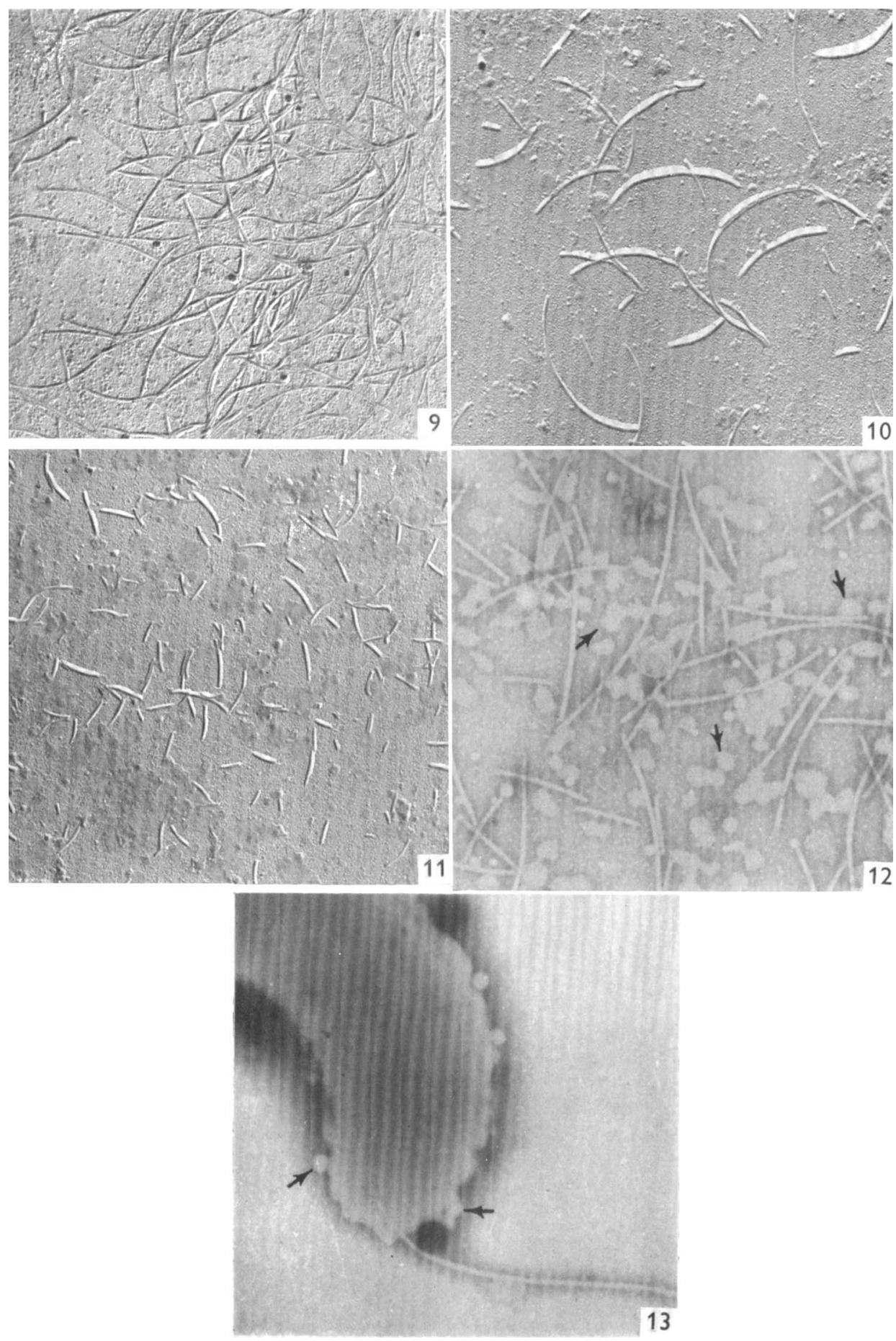

R. F. KEELER AND OTHERS 

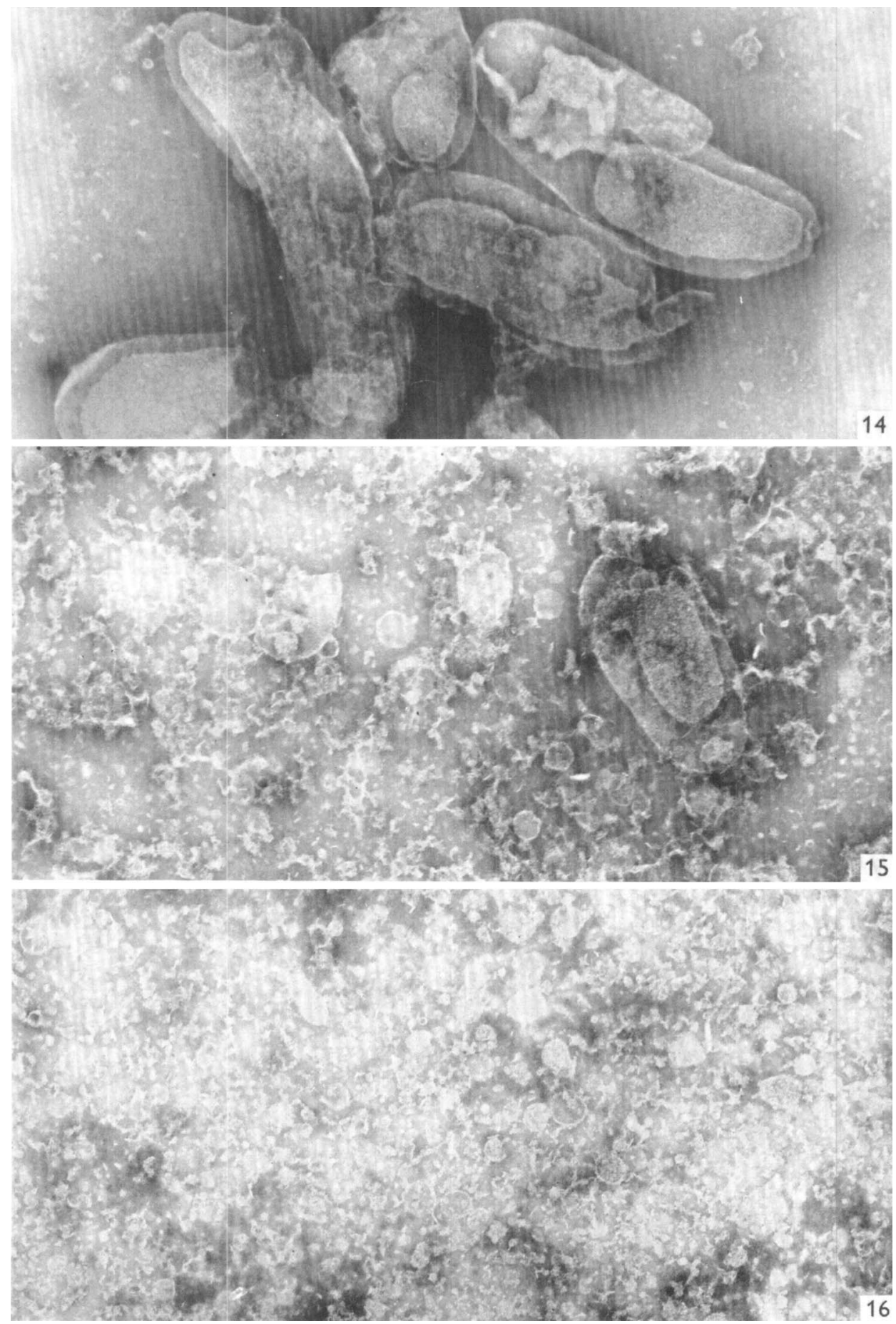

\section{R. F. KEELER AND OTHERS}



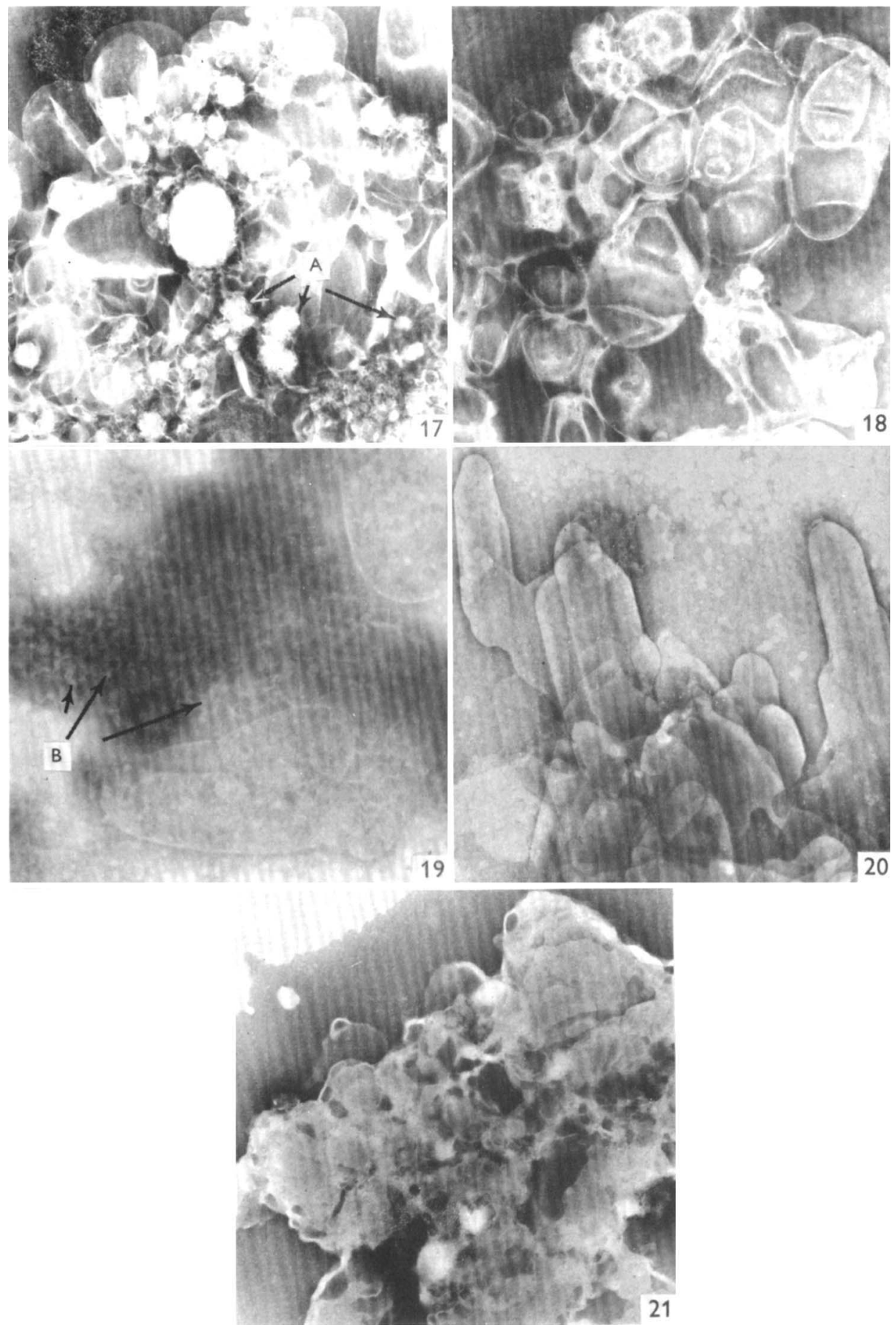

R. F. KEELER AND OTHERS 
Journal of General Microbiology, Vol. 43, No. 3

Plate 6
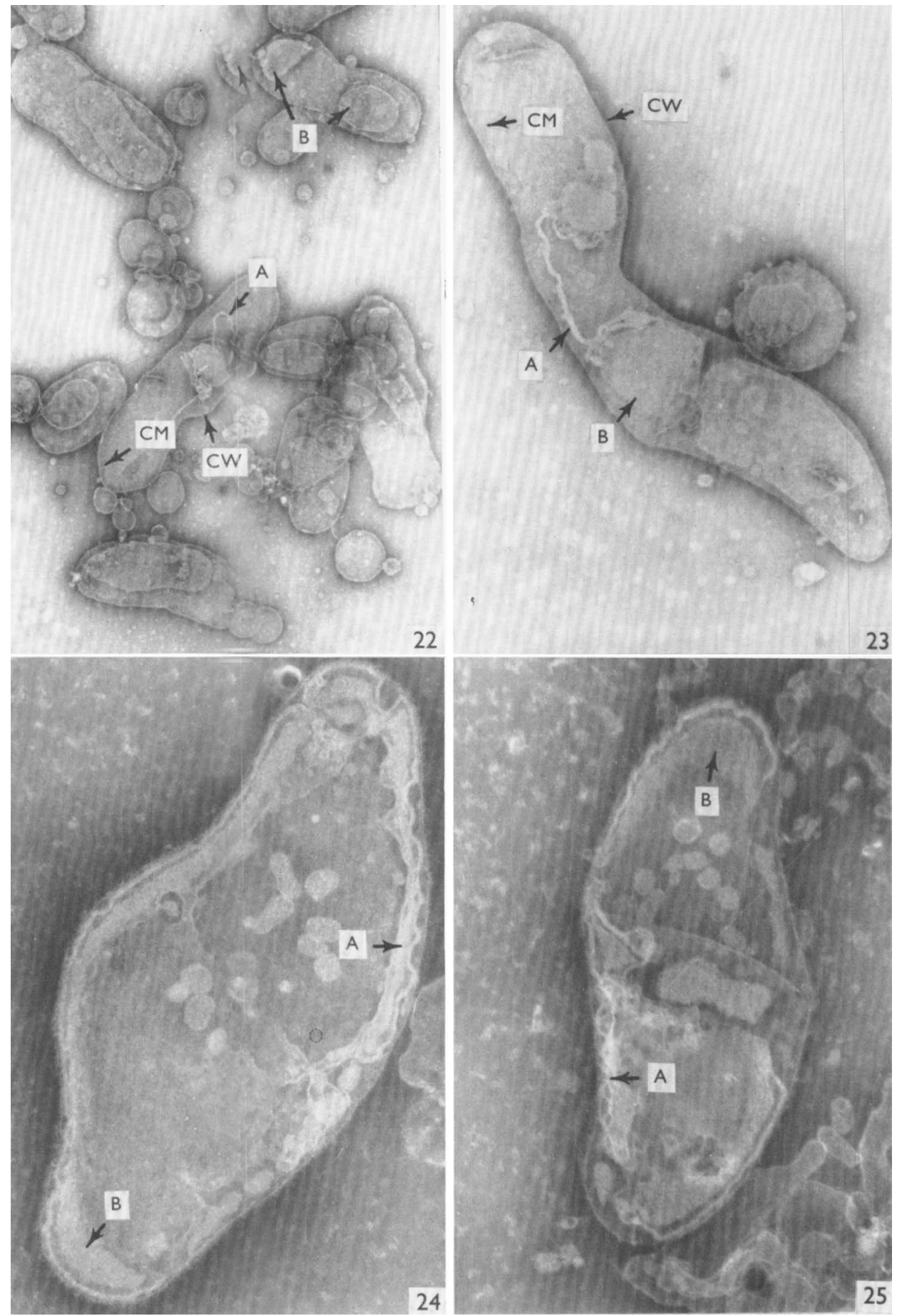

R, F, KEELER AND OTHERS 

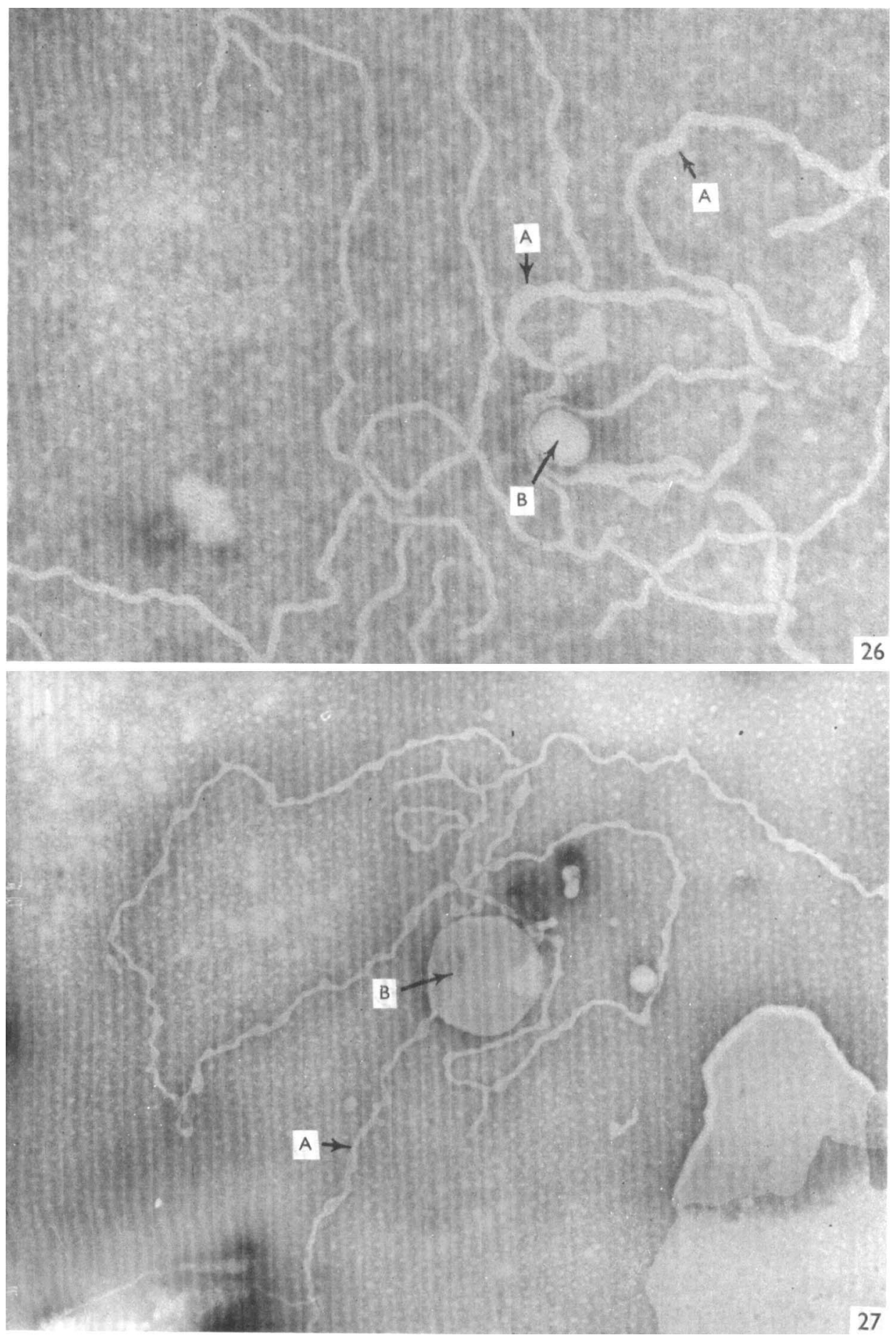

R. F. KEELER AND OTHERS 
Journal of General Microbiology, Vol. 43, No. 3

Plate 8

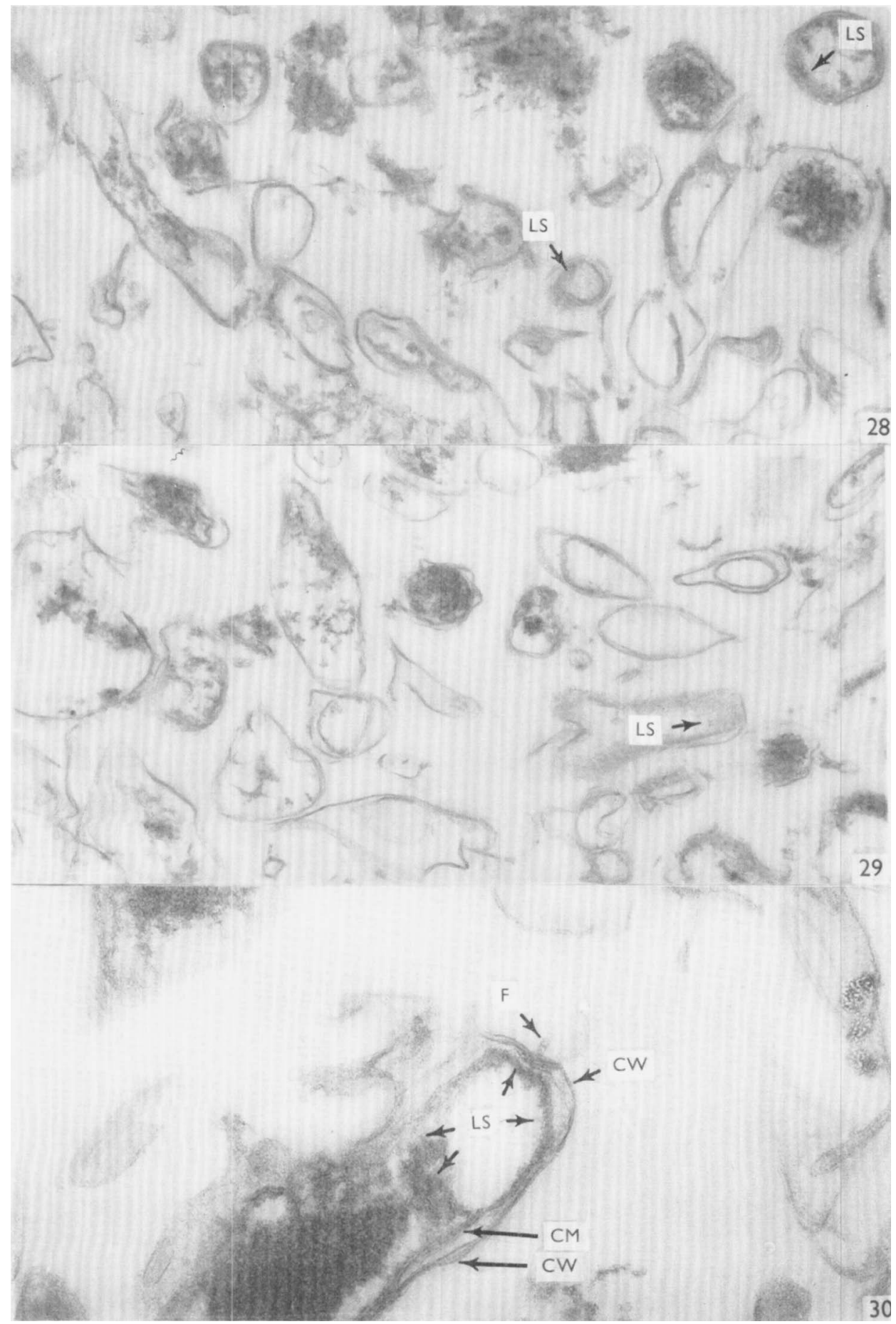

R. F. KEELER AND OTHERS 